\title{
Inflammatory Biomarkers and Liver Histopathology in Non-Uremic and Uremic Chronic Hepatitis C Patients
}

\author{
Bengu Tatar ${ }^{1, *}$, Sukran Kose ${ }^{1}$, Emel Pala², Erhan Tatar ${ }^{3}$
}

\begin{abstract}
Background: The aim of this study is to investigate the association between hepatic activity index (HAI) and fibrosis score (FS) with inflammation biomarkers in non-uremic and uremic hepatitis $\mathrm{C}$ positive patients. Methods: Fifty chronic hepatitis $\mathrm{C}$ (cHepC) positive patients, having a liver biopsy were included in this study. Liver biopsies were scored according to modified ISHAC scoring system. 25 healthy controls of similar age and gender were also enrolled as control group. Serum YKL-40, neutrophil/lymphocyte ratio (NLR), thrombocyte/lymphocyte ratio (PLR), CRP and Immunoglobulin (IgG, A and M) levels were used to determine inflammation. AST to Platelet Ratio Index (APRI) score was also evaluated. According to biopsy findings patients were divided into 2 groups: low (0-2) and severe (3-6) FS. Results: Patients with cHepC had increased inflammation compared to the healthy controls. End-stage renal disease (ESRD) patients had higher levels of inflammation markers (NLR, IgG, CRP and YKL-40) and lower HCV RNA levels, HAI and FS compared to non-uremic patients. When patients were grouped into 2 according to FS as mild and severe, IgG $(p<0.001), Y K L-40(p=0.02)$ levels and APRI score $(p=0.002)$ were significantly higher compared to mild FS $(p=0.002)$. YKL-40 levels ( $t$ value: $3.48 ; p=0.001)$ and APRI score ( $t$ value: 4.57 , $p<0.001$ ) were found as independent associated with FS in non-uremic patients. However, in adjusted models, only APRI score (t value: $3.98, \mathrm{p}=0.002$ ) was an independent associated with FS in ESRD patients. Conclusion: In non-uremic cHepC patients, YKL-40 levels and APRI score may be valuable markers of FS. In ESRD patients, there is not sufficient data for prediction of HAI and FS. In these patients, APRI score may provide better information.
\end{abstract}

\section{KEYWORDS}

APRI score; hepatitis C; end-stage renal disease; inflammation biomarkers; YKL-40; liver histopathology

\section{AUTHOR AFFILIATIONS}

${ }^{1}$ University of Health Science, Izmir Tepecik Education and Research Hospital, Clinic of Infectious Diseases and Clinical Microbiology, Izmir, Turkey

2 University of Health Science, Izmir Tepecik Education and Research Hospital, Pathology, Izmir, Turkey

${ }^{3}$ University of Health Science, Izmir Bozyaka Education and Research Hospital, Department of Nephrology, Izmir, Turkey

* Corresponding author: Izmir Tepecik Education and Research Hospital, Clinic of Infectious Diseass and Clinical Microbiology, +9035110, Konak, Izmir, Turkey; e-mail: b.gtatar@hotmail.com

Received: 11 November 2016

Accepted: 31 July 2017

Published online: 5 October 2017

Acta Medica (Hradec Králové) 2017; 60(2): 71-75

https://doi.org/10.14712/18059694.2017.96

(c) 2017 The Authors. This is an open-access article distributed under the terms of the Creative Commons Attribution License (http://creativecommons.org/licenses/by/4.0), which permits unrestricted use, distribution, and reproduction in any medium, provided the original author and source are credited. 


\section{INTRODUCTION}

It is estimated that $2-3 \%$ of the world population has hepatitis $\mathrm{C}(\mathrm{HepC})$, varying by geographical location, time period and development status of countries $(1,2)$. Important risk factors for $\mathrm{HepC}$ are blood transfusions, solid organ transplantation from an infected donor, i.v. drug use, non-safe therapeutic injections, occupational percutaneous exposures and familial or dialysis-related exposures (3-5). Despite the fact that $\mathrm{HepC}$ incidence and prevalence have declined in the last years, mainly in the hemodialysis population, it is still a major cause of chronic liver disease, cirrhosis and hepatocellular carcinoma $(1,2,5)$.

Liver biopsy is the gold-standard procedure for the diagnosis and treatment decision of HepC. However, it is an invasive procedure, leads to various complications, needs to be repeated and requires hospitalization and is costly. In addition, in uremic patients it may be more difficult to perform due to uremia-related coagulation problems (6). Thus, non-invasive markers are under intense investigation (7) with the literature still being limited.

Inflammatory events play an important role during the course of chronic hepatitis C (cHepC) (8-10). Main contributors are cytokine producing $\mathrm{CD} 4+\mathrm{T}$ and $\mathrm{CD} 8+\mathrm{T}$ cell proliferation, increased CD5+ B cells, IL-2, IFN- $\gamma$ and TNF a (8-10). Neutrophil lymphocyte ratio (NLR) and thrombocyte lymphocyte ratio (PLR) are used as markers of inflammation in various diseases including atherosclerotic heart and renal disease. They are more sensitive compared to total leukocyte counts (11-13). However, there are no data to confirm their use in cHepC patients. Similarly, YKL-40 is a glycoprotein synthesized from neutrophils and macrophages that plays a role in inflammation and tissue remodelling. A number of studies have demonstrated the association between YLK- 40 and fibrosis in liver disease (14-20).

In this study, we aimed to investigate the association between hepatic activity index (HAI) and fibrosis score (FS) with inflammation markers (NLR, PLR, YKL-40, IgG, IgA and IgM) in patients with cHepC with or without endstage renal disease (ESRD).

\section{MATERIAL AND METHODS}

$50 \mathrm{cHepC}$ patients, 15 with ESRD, having undergone percutaneous liver biopsy between December 2011 and June 2013 at a tertiary hospital were included. 25 healthy people $\mathrm{w}$ ith similar age and gender were used as controls. Exclusion criteria were co-infection with other viruses, chronic hepatitis due to other reasons, decompansated cirrhosis, primary or metastaic liver cancers, malignancies, serious congestive heart failure and pyschiatric disorders.

Data on age, gender, smoking, alcohol use, systemic diseases, coinfection, medication, height, weight were obtained from patients charts.

Liver biopsy was performed under ultrasound guidance. İnformed consent was received from all patients prior to biopsy. Modified ISHAC Scoring was used for histopathological evaluation of the liver biopsies. According to biopsy findings patients were divided into 2 groups: low (0-2) and severe (3-6) FS.

NLR, PLR, IgG, IgA, IgM, CRP and YKL-40 levels were measured as markers of inflammation. Serum YKL-40 was detected by ELISA (Human Chitinase 3-Like 1, EuroimmunAnalayser, USA) according to the manufacturer's protocol. APRI score was calculated from 'increase in AST (patient's AST level/upper limit for AST)/Thrombocyte count $\times 100$ '.

In addition to informed consent for liver biopsy, all patients also gave informed consent for this study.

\section{STATISTICAL ANALYSIS}

All analysis were performed by using SPSS 15.0 for Windows. All values are reported as mean \pm SD. The Pearson's Correlation was used for correlation analysis, student t-test and chi-square to compare two groups and ANOVA to compare more than two groups. Stepwise linear regression analysis was used to find independent predictors for HAI and FS. P value less than 0.05 was considered as statistically significant.

\section{RESULTS}

50 patients with cHepC (35 patients were non-uremic cHepC, 15 were ESRD patients) and 25 controls were enrolled. Mean age was $55 \pm 11$ years and $50 \%$ were male. Mean HCV RNA value was $3.6 \mathrm{E}^{+6} \mathrm{IU} / \mathrm{mL} \pm 6.5 \mathrm{E}^{+6} \mathrm{IU} / \mathrm{mL}$. 39 patients had genotype 1,1 was genotype 3 and 4 were genotype 4 (6 patients did not have genotype values). Mean HAI and FS scores were $8.26 \pm 2.22$ and $2.88 \pm 1.54$, respectively.

cHepC patients had similar demographical parameters compared to controls. NLR $(2.52 \pm 1.26$ vs. $1.91 \pm 0.92$; $\mathrm{p}=0.03)$, serum IgG levels $(1491 \pm 459 \mathrm{mg} / \mathrm{dL}$ vs. $1143 \pm$ $229 \mathrm{mg} / \mathrm{dL} ; \mathrm{p}<0.001)$, YKL-40 levels $(134 \pm 170 \mathrm{ng} / \mathrm{mL}$ vs. $18 \pm 9.1 \mathrm{ng} / \mathrm{mL}, \mathrm{p}<0.001)$ were higher in $\mathrm{cHepC}$ patients. There were no differences with regards to total leukocyte count, PLR, CRP, IgM and Ig A levels, whereas liver function tests were higher.

Non-uremic cHepC patients were older, had higher Body mass index (BMI), AST and ALT levels compared to patients with ESRD. In addition, ESRD patients had higher levels of inflammation markers (NLR, IgG, CRP and YKL-40) and lower HCV RNA levels, HAI and FS. These data are presented in Table 1 and Table 2.

In patients with non-uremic $\mathrm{cHepC}$ patients HAI was positively correlated with serum IgG levels $(r=0.400, p=$ $0.017)$, serum IgM levels $(r=0.414, p=0.013)$, GGT levels $(\mathrm{r}=0.511, \mathrm{p}=0.002)$, YKL-40 levels $(\mathrm{r}=0.459, \mathrm{p}=0.006)$ and FS $(\mathrm{r}=0.671, \mathrm{p}<0.001)$. On the other hand, FS was positively correlated with serum IgG levels $(\mathrm{r}=0.519, \mathrm{p}=$ $0.001)$, AST levels $(\mathrm{r}=0.528, \mathrm{p}=0.001)$, ALT levels $(\mathrm{r}=$ $0.427, p=0.010)$, GGT levels $(r=0.439, p=0.008)$, YKL-40 levels $(\mathrm{r}=0.506, \mathrm{p}=0.002)$, APRI score $(\mathrm{r}=0.616, \mathrm{p}<0.001)$ and HAI $(r=0.671, p<0.001)$ and negatively with serum albumin levels $(r=-0.493, p=0.003)$. When patients were grouped into 2 according to FS as mild and severe, AST ( $p=$ $0.005), \operatorname{ALT}(p=0.01), \operatorname{IgG}(p<0.001)$, YKL-40 $(p=0.02)$ 
Tab. 1: Comparison of chepC patients with and without renal failure and controls.

\begin{tabular}{|c|c|c|c|c|}
\hline & Non-Uremic cHepC patients $(\mathrm{N}=35)$ & cHepC patients with ESRD $(\mathrm{N}=15)$ & Controls $(\mathrm{N}=25)$ & P value \\
\hline Age (years) & $59 \pm 9.1$ & $44 \pm 10$ & $57 \pm 10$ & $<0.001$ \\
\hline Gender (M/F) & $17 / 18$ & $8 / 7$ & $13 / 12$ & 0.993 \\
\hline $\mathrm{BMI}\left(\mathrm{kg} / \mathrm{m}^{2}\right)$ & $26 \pm 3.8$ & $22 \pm 2.4$ & $27 \pm 3.6$ & $<0.001$ \\
\hline AST (U/L) & $53 \pm 28$ & $24 \pm 13$ & $24 \pm 16$ & $<0.001$ \\
\hline $\operatorname{ALT}(U / L)$ & $56 \pm 34$ & $28 \pm 18$ & $30 \pm 26$ & 0.001 \\
\hline $\operatorname{ALP}(U / L)$ & $90 \pm 26$ & $163 \pm 105$ & $78 \pm 25$ & $<0.001$ \\
\hline GGT (U/L) & $57 \pm 48$ & $44 \pm 28$ & $37 \pm 70$ & 0.559 \\
\hline Total Bilirubin & $0.85 \pm 0.35$ & $0.66 \pm 0.24$ & $0.65 \pm 0.25$ & 0.065 \\
\hline Creatinine(mg/dl) & $0.87 \pm 0.18$ & $7.2 \pm 2.5$ & $0.90 \pm 0.15$ & $<0.001$ \\
\hline Uric acid (mg/dl) & $5.8 \pm 3.7$ & $5.20 \pm 1.4$ & $4.9 \pm 1.7$ & 0.671 \\
\hline Hemoglobin (g/dl) & $13.4 \pm 2.0$ & $13.2 \pm 2.0$ & $13.4 \pm 1.6$ & 0.940 \\
\hline Platelets & $208 \pm 96$ & $171 \pm 74$ & $258 \pm 49$ & 0.003 \\
\hline Lökosit $\left(\mathrm{mm}^{3}\right)$ & $6332 \pm 1923$ & $6785 \pm 2461$ & $6749 \pm 1515$ & 0.627 \\
\hline NLR & $2.3 \pm 1.4$ & $2.8 \pm 0.8$ & $1.9 \pm 0.9$ & 0.05 \\
\hline PLR & $134 \pm 109$ & $116 \pm 44$ & $129 \pm 51$ & 0.777 \\
\hline Serum albumin & $4.0 \pm 0.5$ & $4.0 \pm 0.3$ & $4.0 \pm 0.4$ & 0.642 \\
\hline Immunoglobulin G (mg/dL) & $1465 \pm 432$ & $1557 \pm 527$ & $1143 \pm 229$ & 0.004 \\
\hline Immunoglobulin M (mg/dL) & $124 \pm 65$ & $100 \pm 58$ & $112 \pm 52$ & 0.399 \\
\hline Immunoglobulin A (mg/dL) & $234 \pm 116$ & $230 \pm 141$ & $201 \pm 83$ & 0.541 \\
\hline $\mathrm{CRP}(\mathrm{mg} / \mathrm{dL})$ & $0.32 \pm 0.27$ & $1.92 \pm 2.24$ & $0.63 \pm 0.81$ & $<0.001$ \\
\hline Serum YKL-40 (pg/mL) & $76 \pm 128$ & $271 \pm 182$ & $18 \pm 9.1$ & $<0.001$ \\
\hline
\end{tabular}

All results are reported as mean $\pm \mathrm{SD}$. chepC = chronic hepatitis $\mathrm{C}, \mathrm{BMI}=$ Body Mass Index, NLR = Neutrophil/Lymphocyte Ratio, PLR = Platelet/Lymphocyte Ratio, $\mathrm{CRP}=\mathrm{C}$-reactive protein, $\mathrm{ESRD}=$ End stage renal disease

Tab. 2: Comparison of inflammation markers and biopsy parameters in chepC patients with and without renal failure.

\begin{tabular}{|c|c|c|c|}
\hline & $\begin{array}{l}\text { Non-Uremic } \\
\text { cHepC } \\
\text { patients } \\
(\mathrm{N}=35), \\
\text { Mean } \pm \mathrm{SD}\end{array}$ & $\begin{array}{l}\text { cHepC } \\
\text { patients } \\
\text { with ESRD } \\
(\mathrm{N}=15), \\
\text { Mean } \pm \text { SD }\end{array}$ & $P$ value \\
\hline NLR & $2.3 \pm 1.4$ & $2.8 \pm 0.8$ & 0.159 \\
\hline $\operatorname{CRP}(\mathrm{mg} / \mathrm{dl})$ & $0.32 \pm 0.27$ & $1.92 \pm 2.24$ & 0.015 \\
\hline Immunglobulin G (mg/dL) & $1465 \pm 432$ & $1557 \pm 527$ & 0.542 \\
\hline Serum YKL-40 (pg/mL) & $76 \pm 128$ & $271 \pm 182$ & 0.001 \\
\hline APRI score & $0.67 \pm 0.43$ & $0.36 \pm 0.24$ & 0.004 \\
\hline HCV RNA & $\begin{array}{l}4.4 \mathrm{E}^{+6} \pm \\
7.7 \mathrm{E}^{+6}\end{array}$ & $\begin{array}{l}1.8 \mathrm{E}^{+6} \pm \\
2.9 \mathrm{E}^{+6}\end{array}$ & 0.201 \\
\hline Hepatic Activity Index & $8.77 \pm 2.19$ & $7.07 \pm 1.83$ & 0.011 \\
\hline Fibrosis Score & $3.26 \pm 1.59$ & $2.00 \pm 1.00$ & 0.007 \\
\hline
\end{tabular}

All results are reported as mean $\pm \mathrm{SD}$. chepC $=$ chronic hepatitis C, NLR = Neutrophil/Lymphocyte Ratio, CRP = C-reactive protein , $\mathrm{ESRD}=$ End stage renal disease

levels and APRI score were significantly higher in the latter $(\mathrm{p}=0.002)$.

In stepwise linear regression analysis, serum IgG and GGT levels were found as independent predictors for HAI, whereas YKL-40 levels and APRI score were found as predictors for FS (Table 3).

In patients with ESRD, HAI was positively correlated with age $(r=0.656, p=0.008)$, serum IgG levels $(r=0.632$, $\mathrm{p}=0.011)$, AST levels $(\mathrm{r}=0.538, \mathrm{p}=0.039)$, APRI score $(\mathrm{r}=$ $0.617, \mathrm{p}=0.014)$ and $\mathrm{FS}(\mathrm{r}=0.858, \mathrm{p}<0.001)$. FS was posi-
Tab. 3: Stepwise linear regression analysis for predictors of Hepatic Activity Index and Fibrosis Score in non-uremic cHepC patients.

\begin{tabular}{|l|l|l|l|l|}
\hline & $\begin{array}{l}\text { Standardized } \\
\boldsymbol{\beta} \text { coefficient }\end{array}$ & $\begin{array}{l}\text { Unstandardized } \\
\boldsymbol{\beta} \text { coefficient }\end{array}$ & t value & P value \\
\hline Hepatic Activity Index, $r^{2}=0.414$ & 0.392 & 2.89 & 0.007 \\
\hline IgG levels & 0.02 & 0.392 & 3.72 & 0.001 \\
\hline GGT & 0.21 & 0.524 & 3.48 & 0.001 \\
\hline Fibrosis Score, $r^{2}=0.550$ & 0.418 & 4.57 & $<0.001$ \\
\hline YKL 40 level & 0.005 & 0.549 &
\end{tabular}

Included variables: Age, IgG, GGT and YKL40 for HAl and age, IgG, APRI and YKL40 for FS.

tively correlated with age $(\mathrm{r}=0.507, \mathrm{p}=0.04)$, AST levels $(\mathrm{r}=0.610, \mathrm{p}=0.016)$, APRI score $(\mathrm{r}=0.733, \mathrm{p}=0.002)$ and HAI $(r=0.858, p<0.001)$ and negatively with thrombocyte count $(\mathrm{r}=-0.563, \mathrm{p}=0.029)$. When patients were grouped into 2 according to FS as mild (67\%) and severe (33\%), AST $(\mathrm{p}=0.005), \operatorname{ALT}(\mathrm{p}=0.01), \operatorname{IgG}(\mathrm{p}<0.001)$, YKL-40 $(\mathrm{p}=$ $0.02)$ and APRI score $(p=0.002)$ were higher in the severe group. These patients were older ( $40 \pm 7.7$ vs. $53 \pm 10$; $\mathrm{p}=$ $0.01)$ and had higher APRI score $(0.28 \pm 0.21$ vs. $0.53 \pm 0.21$, $\mathrm{p}=0.06)$.

In stepwise linear regression analysis (variables: age, IgG, APRI and YKL40), age ( $t$ value $=2.97, p=0.011$ ) and APRI score were independent predictors for HAI ( $t$ value = $2.68, \mathrm{p}=0.020$ ). For FS, only APRI score was an independent predictor ( $t$ value $=3.98, p=0.002$ ) (variables: Age, IgG, APRI and YKL40). 


\section{DISCUSSION}

The results of our study show that YKL-40 levels are independently associated with FS in non-uremic cHepC patients. A similar association could not be confirmed in patients with ESRD.

Many noninvasive biomarkers of fibrosis will be crucial for successful individualized management of disease activity in cHepC patients (7). Currently studies have reported a relation between laminin, hyaluronic acid, type IV collagen, fibronectin, matrix metalloproteinases, metalloproteinase inhibitors, procollagen type III N-terminal propeptide and serum YKL-40 levels with liver fibrosis $(7,15)$.

YKL-40 is a glycoprotein that plays a role in inflammation and tissue remodelling (14). There remains a controversy regarding the role of YKL-40 in patients with cHepC (7, 16-20). Saitou et al. (16) reported increased levels of YKL-40 in 109 patients with cHepc having severe fibrosis. Hovewer, this could not be confirmed in renal transplant patients or hemodialysis patients $(18,20)$. In a genetics-based study, Berres et al. reported increased YKL-40 levels in patients with 131G->C polymorphism of the CHI3L1, which were associated with fibrosis. They also reported the protective effect of the $G$ allele (19). In our study, serum YKL-40 levels were correlated with HAI and FS in non-uremic patients and independently associated with FS. However, this finding could not be confirmed in ESRD patients. This may be due to several reasons. Firstly, our study population was relatively small therefore results reaching a statistical power. Secondly, YKL-40 is excreted by the kidneys and the levels are very high compared to non-uremic patients. This may have a limiting effect by interfering with the equations in the statistical analysis. Thirdly, increased inflammation in dialysis patients may be interfering with the YKL-40 measurements (like the abnormal levels of ferritin in the same population) Fourthly but not the last, the fact that the increased levels of YKL-40 are mainly seen in patients with severe fibrosis, less frequency of FS in uremic patients may be limiting the association. Thus, we propose that YKL-40 measurement may provide limited information in ESRD patients.

High IgG levels in cHepC patients have been shown to affect prognosis and response to therapy (21-24). Maruyama et al. (21), reported a correlation between serum IgG levels and the severity of the disease in 102 patients with cHepC and significant decrease in levels by treatment. Gonzàlez-Quintela et al. and Watt et al. also described significantly higher levels of IgG and IgA in patients with cHepC $(22,23)$. Our results further confirm these studies: significantly higher immunoglobulin levels in cHepC patients compared to controls and correlation of IgG with $\mathrm{HAI}$ and FS in non-uremic patients. The association between HAI and IgG was independent. Similar to YKL-40, the association among IgG, HAI and FS could not confirm in ESRD patients.

In ESRD patients, we could not find an association between HAI and FS with the inflammation biomarkers. The most plausible reason may the confounding effect of inflammation due to uremia and in some patients due to comorbid diseases. On the other hand, the decreased vi- ral load by hemodialysis, the release of protective IFN- $a$ and hepatocyte growth factor and relatively lower FS may be affecting the association of inflammatory marker with fibrosis. Thus, the role of these markers may be questionable in ESRD patients.

APRI score is used to predict liver fibrosis in cHepC patients. Schiavon et al. reported a positive predictive value of $66 \%$ for fibrosis (METAVIR F2, F3 and F4) when APRI $>0.95$ and negative predictive value of $93 \%$ when APRI $<0.40$ in ESRD patients (17). In another study by the same group, APRI score was found to be superior to YKL-40 with regards to fibrosis in ESRD patients (18). In our study, we found APRI score as an independent predictor for both HAI and FS. Thus, APRI score might be a valuable score to predict FS in ESRD patients.

NLR and PLR are current markers of interest for systemic inflammation (11-13). Data is limited in patients with cHepC. In one study, NLR was proposed as related to viral load and as an independent marker to follow response to therapy, especially in genotype 2 patients (25). We could not confirm any association neither with HAI or FS. Further studies are needed to investigate the role of NLR and PLR in this population.

There are several limitations to our study. The study population is relatively low and this may have prevented some statistical analysis to reach a statistical significance. Also, the majority of the patients were genotype $1 \mathrm{cHepC}$ patients and our results may not be valid for all genotypes. The biopsies were scored according to the modified ISAAC scoring system and therefore, other scoring systems may yield different results. Finally, the relatively low FS observed in the patients may have interfered with the analysis.

As a conclusion, YKL-40 may be a valuable marker to predict fibrosis in non-uremic patients with cHepC. Serum IgG and GGT levels, used frequently in routine practice, may be also good predictors for HAI. However, the role of inflammatory markers in the prediction of HAI and FS may be limited in ESRD patients. In this population, APRI score may provide useful information with regards to HAI and FS.

\section{ACKNOWLEDGEMENTS}

This study was not funded any financial support.

\section{CONFLICT OF INTEREST}

Declare no conflict of interest.

\section{INFORMED CONSENT}

Informed consent was obtained from all individual participants included in the study.

\section{REFERENCES}

1. Freeman AJ, Dore GJ, Law MG, et al. Estimating progression to cirrhosis in chronic hepatitis $C$ virus infection. Hepatology 2001; 34 : 809-816.

2. Lavanchy D. The global burden of hepatitis C. Liver Int 2009; 29(Suppl 19): 74-81. 
3. Williams IT, Bell BP, Kuhnert W, Alter MJ. Incidence and transmission patterns of acute hepatitis C in the United States, 1982-2006. Arch Intern Med 2011; 171: 242-8.

4. Calvaruso V, Craxi A. 2011 Europian Association of THA Study of Liver hepatitis C virus clinical practice guidelines. Liver Int 2012; 32(Suppl 1): 2-8.

5. Marinaki S, Boletis JN, Sakellariou S, Delladetsima IK. Hepatitis C in hemodialysis patients. World J Hepatol 2015; 7: 548-58.

6. Strassburg CP, Manns MP. Approaches to liver biopsy techniques revisited. Semin Liver Dis 2006; 26: 318-27.

7. Sebastiani G, Alberti A. How far is noninvasive assessment of liver fibrosis from replacing liver biopsy in hepatitis C? J Viral Hepat 2012; 19(Suppl 1): 18-32.

8. Gremion C, Cerny A. Hepatitis C virus and the immune system: a concise review. Rev Med Virol 2005: 15: 235-68.

9. Curry MP, Golden-mason L, Nolan N, et al. Expansion of peripheral blood CD $5+\mathrm{B}$ cells is associated with mild disease in chronic $\mathrm{C}$ virus infection. J Hepatol 2000; 32: 121-5.

10. Ishii S, Koziel MJ. Immune responses during acute and chronic infection with hepatitis C virus. Clin Immunol 2008; 128: 133-47.

11. Bhat T, Teli S, Rijal J, et al. Neutrophil to lymphocyte ratio and cardiovascular diseases: a review. Expert Rev Cardiovasc Ther 2013; 11: 55-9.

12. Tatar E, Mirili C, Isikyakar T, et al. The association of neutrophil/ lymphocyte ratio and platelet/lymphocyte ratio with clinical outcomes in geriatric patients with stage 3-5 chronic kidney disease. Acta Clin Belg 2016; 71: 221-6.

13. Ayça B, Akin F, Celik O, et al. Platelet to lymphocyte ratio as a prognostic marker in primary percutaneous coronary intervention. Platelets 2015; 26: 638-44.

14. Johansen JS. Studies on serum YKL-40 as a biomarker in diseases with inflammation, tissue remodelling, fibroses and cancer. Dan Med Bull 2006; 53: 172-209.

15. Amorim TG, Staub GJ, Lazzarotto C, et al. Validation and comparison of simple noninvasive models for the prediction of liver fibrosis in chronic hepatitis C. Ann Hepatol 2012; 11: 855-61.
16. Saitou Y, Shiraki K, Yamanaka Y, et al. Noninvasive estimation of liver fibrosis and response to interferon therapy by a serum fibrogenesis marker, YKL-40, in patients with HCV-associated liver disease. World J Gastroenterol 2005; 11: 476-81.

17. Schiavon LL, Schiavon JL, Filho RJ, et al. Simple blood tests as noninvasive markers of liver fibrosis in hemodialysis patients with chronic hepatitis C virus infection. Hepatology 2007; 46: 307-14.

18. Schiavon LL, Narciso-Schiavon JL, Carvalho Filho RJ, et al. Serum levels of YKL-40 and hyaluronic acid as noninvasive markers of liver fibrosis in haemodialysis patients with chronic hepatitis $C$ virus infection. J Viral Hepat 2008; 15: 666-74.

19. Berres ML, Papen S, Pauels K, et al. A functional variation in CHI3L1 is associated with severity of liver fibrosis and YKL-40 serum levels in chronic hepatitis C infection. J Hepatol 2009; 50: 370-6.

20. Schiavon LL, Carvalho-Filho RJ, Narciso-Schiavon JL, et al. YKL-40 and hyaluronic acid (HA) as noninvasive markers of liver fibrosis in kidney transplant patients with HCV chronic infection. Scand J Gastroenterol 2010; 45: 615-22.

21. Maruyama S, Hirayama C, Horie Y, et al. Serum immunoglobulins in patients with chronic hepatitis $\mathrm{C}$ : a surrogate marker of disease severity and treatment outcome. Hepatogastroenterology 2007; 54: 493-8.

22. Gonzàlez-Quintela A, Alende MR, Gamallo R, et al. Serum immunoglobulins (IgG, IgA, IgM) in chronic hepatitis C. A comparison with non-cirrhotic alcoholic liver disease. Hepatogastroenterology 2003; 50: 2121-6.

23. Watt K, Uhanova J, Gong Y, Kaita K, Doucette K, Pettigrew N, et al. Serum immunoglobulins predict the extent of hepatic fibrosis in patients with chronic hepatitis C virus infection. J Viral Hepat 2004; 11: 251-6.

24. Schmilovitz-Weiss H, Cohen M, Pappo O, et al. Serum globulin levels in predicting the extent of hepatic fibrosis in patients with recurrent post-transplant hepatitis C infection. Clin Transplant 2007; 21: 391-7.

25. Kuo MT, Hu TH, Lu SN, et al. Neutrophil-to-lymphocyte ratio as a predictor of response to peginterferon plus ribavirin therapy for chronic hepatitis C. Dis Markers 2014; 2014: 462958. 